\title{
Why does SEPR publish people's COVID-19 experience, observations, and reflections?
}

\author{
Wei-Ning Xiang ${ }^{1}$
}

○) Springer Nature Singapore Pte Ltd. 2020

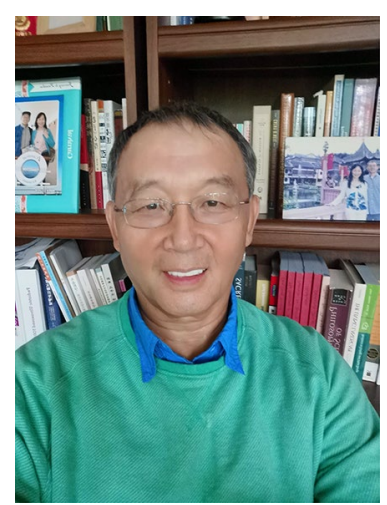

The editor in chief of SEPR and editor of the special theme section

To the 74 colleagues from 14 countries on 6 continents/regions whose enthusiastic participation and generous support made this special SEPR section possible

\section{Why are people's COVID-19 experience, observations, and reflections of interest?}

"Why do you aim at documenting personal COVID-19 experience, observations, and reflections?" "How did you happen to pick the theme of "compassion and collaboration'?" Asked two authors in their emails to me dated, respectively, April 21 and May 18, 2020. ${ }^{1}$

Wei-Ning Xiang

wxiang@uncc.edu

1 University of North Carolina at Charlotte, Charlotte, USA
What they referred to is the following statement of purpose I wrote for the special theme section in this journal Fighting the COVID-19 pandemic with compassion and collaboration for the community of shared future (copyedited for this editorial) ${ }^{2}$ :

Through this special collection of articles, I aim to document people's COVID-19 experience, their observations and reflections during the pandemic. All are under the three keywords: compassion, collaboration, a community of shared future.

Their questions were exactly appropriate, and I responded swiftly via brief emails. Later, envisioning that more people would ask similar questions when reading articles in the special theme section, I decided to further develop the email responses into an editorial as an introduction to the special section. For this purpose, I translated the original queries into the following self-questions:

(1) Why am I interested in documenting people's stories of personal compassion and collaboration experience, and publishing their observations and reflections during the COVID-19 pandemic?

(2) Why do I think articles about people's experience, observations, and reflections fit the journal SocioEcological Practice Research (SEPR)?

(3) What is it that inspired me to develop a special SEPR section about people, compassion and collaboration in the COVID-19 pandemic?

One by one I answer these questions in the following three sections.

\footnotetext{
${ }^{1}$ I was given the permission to use their emails in this editorial on the condition that the authors be kept anonymous. Both questions were copyedited for the editorial.

2 The statement of purpose was in the Call for Prospectus which was sent out on April 20, 2020. In September 2020, the special section was published in Socio-Ecological Practice Research (SEPR) [2020, volume 2 , issue 3 (this issue)].
} 


\section{People's COVID-19 experience, observations, and reflections are worth documenting}

This section title highlights my answer to the first question.

\subsection{Personal stories help build a written COVID-19 history with people in it}

People's stories of personal compassion and collaboration experience beg to be told and documented if and when they provide fine-grain, vivid accounts of affective incidents or events individual persons experienced during the COVID-19 pandemic. Further, besides the vantage point the storyteller took, such an account could also be reflective, and therefore indicative, of socio-ecological, political, and economic circumstances in which the incident or event took place in a specific place and time during the pandemic. As such, documenting stories of personal compassion and collaboration experience is worthwhile for at least three reasons: the storytellers and people in the stories; the sheer dramas of their tales; and a noble historical purpose-documenting the sensational nuances of compassion and collaboration in these stories as part of a larger whole of COVID-19 history with ordinary people in it. ${ }^{3}$

These documented stories of personal compassion and collaboration experience and a written people's history of the COVID-19 pandemic they contribute to, once completed, will be an invaluable heritage of the humanity. Among other benefits, it will help us and our posterity to discern and appreciate the real meaning and true value of humanity's interconnectedness in the face of this hitherto unprecedented calamity. That is, no sentient being is exempt from suffering, suffering is a shared human experience; everyone deserves compassion, including oneself (Chen and Xiang 2020b); we are indeed a community of shared past, present and future (Douglas 2020; Hu 2020; Wang 2020, p.183; Zheng 2020).

\footnotetext{
3 The idea a written history with people in it is inspired by Japanese historian Yoshiaki Yoshimi and by his book Grassroots fascism (Yoshiaki 2015). Early in his career, Yoshiaki Yoshimi "was dissatisfied with the near-universal academic focus (among Japanese historians in the 1960s) on elites and abstract social structures that rendered the story of the Japanese experience of the (second world) war 'a history without people in it"' (Mark 2015, p. 6; parentheses by the author of this editorial). To write a history of personal war experience, he conducted a nuanced, critical yet compassionate examination of the diaries of repatriated soldiers and other personal documents written during or shortly after the war (Mark 2015, pp. 15-16), and published his findings in 1987 [For the English editions of his works on this topic, see Yoshiaki (2012, 2015); see also Palko and Xiang (2020)].
}

\subsection{Personal observations and reflections "open new layers of knowledge"}

It is a commonplace that personal observations and reflections deserve to be shared and preserved if and when they provide new and nuanced insights useful to others [for general references with examples, see Mark 2015; Thoresen and Öhlén 2015; Yoshiaki 2015, among others]. Further, an individual's observations and reflections based on his/her firsthand compassion and collaboration experience during the COVID-19 pandemic are not just mental, spiritual and intellectual assets for personal growth and flourishing. They can also trigger intriguing yet profound questions prompting oneself or others to search for novel insights (Hayek 1952, pp. 18-19); if following through, people may most likely find deeper, more systematic answers to the questions raised (Ibid., p. 19), and thus "open new layers of knowledge" (Thoresen and Öhlén 2015, p. 1593).

All these nuggets of novel understanding derived from people's real-world COVID-19 experience may very well contribute to a new body of knowledge of common threat planning and management. So do the intriguing research questions raised. A common threat is by definition a danger-something or someone that can hurt or harm peoplethat might happen to every individual human being in a certain place (e.g., the earth, a country, a region, a city, a village, a community, etc.) to the extent that no one in that place is immune. A common threat comes either from a natural disaster or human conflict. At the global scale, for example, the COVID-19 pandemic exemplifies the former, and World War II the latter (Palko and Xiang 2020). Common threat planning and management-how to prepare for and cope with common threats - could most likely be an emerging area of research and practice from now onward thanks to the daunting reality of COVID-19 pandemic being experienced by the entire humanity in the world.

Documenting people's observations and reflections on their personal compassion and collaboration experience is therefore worthwhile for at least three reasons: sharing and preserving the new insights, raising and recording intriguing research questions for deeper understanding; helping build the practice and science of common threat planning and management.

\section{Articles being ecopracticological are SEPR suitable}

The sentence in the section title summarizes my answer to the second question.

The journal SEPR is about ecopracticology — the study of socio-ecological practice (Xiang 2019a, b); it as such invites and welcomes articles that are ecopracticological by nature. 
Table 1 A presence/ absence assessment of article ecopracticologability

\begin{tabular}{llllllll}
\hline Special section articles & \multicolumn{7}{l}{ P/A Ecopracticologability assessment results } \\
\cline { 2 - 7 } & 1 & 2 & 3 & 4 & 5 & 6 & 7 \\
\hline Chen and Yuan (2020) & $\mathrm{x}$ & $\mathrm{x}$ & $\mathrm{x}$ & $\mathrm{x}$ & & & \\
Douglas (2020) & $\mathrm{x}$ & $\mathrm{x}$ & $\mathrm{x}$ & $\mathrm{x}$ & & $\mathrm{x}$ & \\
Douglas et al. (2020) & $\mathrm{x}$ & & & $\mathrm{x}$ & $\mathrm{x}$ & $\mathrm{x}$ & \\
Forester and McKibbon (2020) & $\mathrm{x}$ & $\mathrm{x}$ & $\mathrm{x}$ & $\mathrm{x}$ & $\mathrm{x}$ & $\mathrm{x}$ & $\mathrm{x}$ \\
Hu (2020) & $\mathrm{x}$ & $\mathrm{x}$ & & $\mathrm{x}$ & & $\mathrm{x}$ & \\
Niner et al. (2020) & $\mathrm{x}$ & $\mathrm{x}$ & $\mathrm{x}$ & $\mathrm{x}$ & & & \\
Palko and Xiang (2020) & $\mathrm{x}$ & & & $\mathrm{x}$ & $\mathrm{x}$ & $\mathrm{x}$ & $\mathrm{x}$ \\
Wang (2020) & $\mathrm{x}$ & $\mathrm{x}$ & & $\mathrm{x}$ & & & $\mathrm{x}$ \\
Zheng (2020) & $\mathrm{x}$ & $\mathrm{x}$ & & $\mathrm{x}$ & & & $\mathrm{x}$ \\
\hline
\end{tabular}

Numbers 1-7 represent the seven criteria undermentioned; $x$ stands for satisfaction, blank unsatisfaction; Chen and Yuan 2020 and Wang 2020 are published in SEPR 2(2)
Broadly speaking, an article is ecopracticological if it meets any combination of the following criteria.

(1) taking socio-ecological practice as an object of study, with a focus on one or any combination of its six components_planning, design, construction, restoration, conservation, and management (Xiang 2019b, p. 7, p. 10 ; this is the sine qua non);

(2) regarding socio-ecological practice as both a system of systems and a system among systems (Ibid., p. 8);

(3) accepting the daunting realities of wickedness and original flaw as the norm, and taking trial and error and evolutionary tinkering as the basic coping strategies (Ibid.);

(4) respecting ordinary people and practitioners (Ibid., p. 19), learning and critically reflecting on what they do in socio-ecological practice and what logic of practice they follow (Ibid., p. 8);

(5) recognizing the importance of leadership and decisive role leaders play in socio-ecological practice (Ibid., p. 9);

(6) valuing an eclectic, pragmatic, yet ethical approach to both socio-ecological practice and research (Ibid., pp. 9-12);

(7) using examples of good or bad socio-ecological practice as a primary vehicle for theorizing, putting good examples before prevalent theories.

Articles would likely be ecopracticological and thus suitable for SEPR when sharing people's stories of personal compassion and collaboration experience, and/or documenting their observations and reflections during the COVID-19 pandemic. That was what I had in mind and hoped for when writing the Call for Prospectus in April; and, luckily, that also turned to be the case. Most manuscripts submitted to SEPR for the special compassion and collaboration section met at least two of the above seven criteria. Those that are published and included in the special section met more. Table 1 lists these articles with results of a presence/absence assessment by me. How could such an amazing result be possible? It was achieved, I consider, through a combination of dogged perseverance of our special section development team (see Sect. 5) on the one hand and pure fortuitousness of the journal on the other.

\section{There is nothing as inspirational as a good example (Xiang 2020a, p. 126)}

To the third self-question raised in section 1 , my answer is that it is the good examples from practice that inspired me to develop a special SEPR section about people, compassion and collaboration in the COVID-19 pandemic.

\subsection{Inspired by practitioners and their good deeds in the Red Flag Canal project}

Since January 2020, I have been reading and studying the compassion and collaboration literatures in English and Chinese languages as part of my research on the Red Flag Canal, a 50-plus-year-old irrigation canal in Henan Province, China. ${ }^{4}$

I found that one reason for the canal project's success is the strong support from the top leaders of the two provinces, Henan and Shanxi. These leaders all lived and worked in Linxin County (where the canal water is conveyed to) during the wartime in the 1940s, and they therefore had strong attachment to the people and place. From these personal experiences, they not only felt vividly the continuous suffering of the Linxian people from the hardships of water shortage; but were also able to develop and sustain a strong desire to help alleviate Linxian people's suffering. I learnt that this dual mental state, the sympathetic emotion and concomitant desire to help, is compassion; and that the series of prosocial actions they took in 1960 to support the Red Flag

\footnotetext{
${ }^{4}$ Readers who are interested in our Red Flag Canal research can read
} Xiang (2020b) and Chen and Xiang (2020a, b). 
Canal project were impelled by the desire, and therefore are manifestations of compassion in this great instance of socioecological practice (Chen and Xiang 2020a, b).

Furthermore, in order to divert water from Pingshun County in the neighbor Shanxi province, the Linxian people needed to win their neighbor's support and make sure that the Pingshun people was a winner as well. Working together, the people from both counties figured out how to collaborate, and finally made the project work and work well (Chen and Xiang 2020a). That taught me collaboration in practice.

\subsection{Inspired by what I saw through a lens of compassion and collaboration}

This focus in my Red Flag Canal research on how the practitioners exercised compassion and collaboration effectively in their socio-ecological practice is not just fruitful. It furnishes me a humane lens of compassion and collaboration to view and discern the world.

Through this lens, I was able to see the COVID-19 pandemic as a common threat to the entire humanity in the world and to understand compassion and collaboration as innate human abilities essential for survival and wellbeing in the face of a calamity (Chen and Xiang 2020b). As the Dutch social psychologist Geert Hofstede (1928-2020) once said, "The survival of mankind will depend to a large extent on the ability of people who think differently to act together" (Hofstede 2001, p. xv; italics by the author of this editorial).

Through this lens, I have been reading news reports on the COVID-19 pandemic every day since the late January 2020. I was constantly moved by touching stories from different parts of the world about how ordinary people acted compassionately and collaboratively in their daily combat against the pandemic. I was inspired to follow their lead and join the combat. The desire kept building up and reached its peak in the mid-April when two COVID-19 articles I commissioned (i.e., Chen and Yuan 2020; Wang 2020) were published in SEPR and immediately well-received. Decided to develop a special SEPR section with a theme on compassion and collaboration in the COVID-19 combat, I sent out the Call for Prospectus on April 20.

Having answered the three self-questions raised in Sect. 1, I now conclude this editorial with acknowledgments to the people who made this special theme section possible.

\section{A tribute to our special section development team}

The development of this special theme section is a great teamwork. A total of 74 passionate colleagues from 14 countries on 6 continents/regions converged on this timely
Table 2 The SEPR team of special theme section development: 74 authors/reviewers from 14 countries on 6 continents/regions

\begin{tabular}{lll}
\hline Continent/region & Country & $\begin{array}{l}\text { Authors/ } \\
\text { reviewers }\end{array}$ \\
\hline Africa & Kenya & 1 \\
Asia & China & 10 \\
& Singapore & 1 \\
Europe & Germany & 3 \\
& Ireland & 1 \\
& Netherlands & 1 \\
& Norway & 1 \\
& Poland & 1 \\
North America & UK & 10 \\
& Canada & 1 \\
Oceania & USA & 38 \\
South America & Australia & 4 \\
& Brazil & 1 \\
& Chile & 1 \\
\hline
\end{tabular}

Each of the 74 team members will be honored in the annual acknowledgments to SEPR authors and reviewers

and important theme Fighting the COVID-19 pandemic with compassion and collaboration for the community of shared future. They worked diligently and collaboratively, whether as authors, reviewers, or both, toward a common aim-dedicating the best of their scholarship to the global combat against this hitherto unprecedented common threat (Table 2).

The outstanding teamwork sets new record. From launching the Call for Prospectus to accepting the last manuscript, it took a little over four months. This is the most remarkable speed in my 9-year editorial experience [the coeditor in chief of Landscape and Urban Planning (2011-2018); the founding editor in chief of Socio-Ecological Practice Research (2019-present)]. A typical turnaround is $12-18$ months. The great teamwork of all 74 colleagues made this possible.

Finanly, to all the 74 colleagues on the team, I am very grateful for your support and participation during the development of this special theme section; and hope that we can work together again in the development of the new SEPR special issue Envisioning alternative futures of socio-ecological practice: navigating an uncertain world with a compass of scenarios (For the Call for Prospectus, see Xiang 2020c).

To the readers of this special theme section, I hope you enjoy reading and find the contents useful; and cordially I invite you to become a SEPR author, a reviewer, or both.

Acknowledgments I thank Ying Chen (Tongji University, Shanghai, China) for designing Table 2; and thank the two special section authors who gave me the permission to use their emails in this editorial. 


\section{References}

Chen Y, Xiang W-N (2020a) Why was Tao Lujia so willing and swift to greenlight the Red Flag Canal Project in 1960? The instance and his reflections. Socio-Ecolog Practice Res. https://doi. org/10.1007/s42532-020-00060-5

Chen Y, Xiang W-N (2020b) Why was Tao Lujia so willing and swift to greenlight the Red Flag Canal Project in 1960? New insights via a lens of compassion practice. Socio-Ecolog Practice Res. https ://doi.org/10.1007/s42532-020-00061-4

Chen L, Yuan X (2020) China's ongoing battle against the coronavirus: why did the lockdown strategy work well? Socio-Ecolog Practice Res 2(2):175-180. https://doi.org/10.1007/s42532-020-00048-1

Douglas I (2020) COVID-19 compassion in self-isolating old age: looking forward from family to regional and global concerns. Socio-Ecolog Practice Res. https://doi.org/10.1007/s42532-02000053-4

Douglas I, Champion M, Clancy J et al (2020) COVID-19 and socioecological practice research in urban ecology set in a global context. Socio-Ecolog Practice Res. https://doi.org/10.1007/s4253 2-020-00067-y

Forester J, McKibbon G (2020) Beyond blame: leadership, collaboration and compassion in the time of COVID-19. Socio-Ecolog Practice Res. https://doi.org/10.1007/s42532-020-00057-0

Hayek FA (1952) Counter-revolution of science: studies on the abuse of reason. The Free Press, Glencoe

Hofstede G (2001) Culture's consequences: comparing values, behaviors, institutions, and organizations across nations, 2nd edn. Sage, Thousand Oaks

Hu R (2020) Reinventing community in COVID-19: a case in Canberra. Socio-Ecological Practice, Australia. https://doi.org/10.1007/ s42532-020-00055-2

Mark E (2015) Translator's introduction: the people in the war. In: Yoshiaki Y (2015) Grassroots fascism: the war experience of the Japanese people. Translated and annotated by Ethan Mark, pp 1-39. Columbia University Press, New York

Niner H, Johri S, Meyer J, Wassermann SN (2020) The pandemic push: can COVID-19 reinvent conferences to models rooted in sustainability, equitability and inclusion? Socio-Ecolog Practice Res. https://doi.org/10.1007/s42532-020-00059-y
Palko HC, Xiang W-N (2020) In fighting common threats, people's deep commitment to taking collective action matters: examples from China's COVID-19 battle and her other combats. SocioEcolog Practice Res. https://doi.org/10.1007/s42532-020-00056-1

Thoresen L, Öhlén J (2015) Lived observations: linking the researcher's personal experiences to knowledge development. Qual Health Res 25(11):1589-1598

Wang Y (2020) China's ongoing battle against the coronavirus: a scholar-practitioner's experiences and reflections. Socio-Ecolog Practice Res 2(2):181-183. https://doi.org/10.1007/s42532-02000047-2

Xiang W-N (2019a) Socio-Ecological Practice Research (SEPR): what does the journal have to offer? Socio-Ecolog Practice Res 1(1):15. https://doi.org/10.1007/s42532-018-0001-y

Xiang W-N (2019b) Ecopracticology: the study of socio-ecological practice. Socio-Ecolog Practice Res 1(1):7-14. https://doi. org/10.1007/s42532-019-00006-6

Xiang W-N (2020a) From good practice for good practice we theorize; in small words for big circles we write. Socio-Ecolog Practice Res 2(1):121-128

Xiang W-N (2020b) The Red Flag Canal: a socio-ecological practice miracle from serendipity, through impossibility, to reality. SocioEcolog Practice Res 2(1):105-110. https://doi.org/10.1007/s4253 2-019-00037-z

Xiang W-N (2020c) Envisioning alternative futures of socio-ecological practice: navigating an uncertain world with a compass of scenarios. Socio-Ecolog Practice Res. https://doi.org/10.1007/s4253 2-020-00063-2

Yoshiaki Y (2012) The Second Sino-Japanese war and national mobilization: the issue of rallying soldiers and personal experiences of the battlefield. Translated by Miriam Chusid. Japan Forum, 24(1): 119-130, Doi: 10.1080/09555803.2011.637638 (First published in Japanese in 1987)

Yoshiaki Y (2015) Grassroots fascism: the war experience of the Japanese people. Translated and annotated by Ethan Mark. Columbia University Press, New York (First published in Japanese by University of Tokio press in 1987)

Zheng C (2020) Caring for the self and others: a reflection on everyday commoning amid the COVID-19 pandemic. Socio-Ecolog Practice Res. https://doi.org/10.1007/s42532-020-00062-3 